\title{
Skin Progression GvHD
}

National Cancer Institute

\section{Source}

National Cancer Institute. Skin Progression GvHD. NCI Thesaurus. Code C126725.

An NIH skin score that has increased by 1 or more points, except 0 to 1. 